B I O S C I E N C E

J O U R N A L

\section{QUALITY OF LIFE AND THE WORK CAPACITY OF PROFESSIONAL NURSING STAFF IN THE HOSPITAL ENVIRONMENT}

Cicylia Silveira de LIMA ${ }^{1}$ (D), Ludmila Grego MAIA ${ }^{2}$ iD, Bruno Bordin PELAZZA ${ }^{3}$ (D), Sabrina Toffoli LEITE ${ }^{4}$ (D) , Cristiane José BORGES ${ }^{2}$ (D) , Guilherme Silva de MENDONÇA ${ }^{5}$ iD), Sebastião Elias da SILVEIRA ${ }^{6}$ (iD), Hugo Machado SANCHEZ ${ }^{7}$ (D) Luiz Almeida SILVA $^{8}$ id

${ }^{1}$ Hospital Padre Tiago da Providência de Deus, Jataí, Goiás, Brazil.

2 Undergraduate Nursing Course, Federal University of Jataí, Jataí, Goiás, Brazil.

3 Department of Nursing, State University of the Midwest, Guarapuava, Paraná, Brazil.

${ }^{4}$ Academic Unit of Health Sciences, Federal University of Jataí, Jataí, Goiás, Brazil.

${ }^{5}$ Mental Health Inpatient Unit, Hospital das Clínicas, Federal University of Uberlândia, Uberlândia, Minas Gerais, Brazil.

${ }^{6}$ Hospital das Clínicas, Federal University of Uberlândia, Uberlândia, Minas Gerais, Brazil.

7 Department of Physiotherapy, Federal University of Jataí, Jatai, Goiás, Brazil.

8 Department of Nursing, Federal University of Catalão, Catalão, Goiás, Brazil.

Corresponding author:

Guilherme Silva de Mendonça

Email: guilhermesilvamendonca@gmail.com

How to cite: LIMA, C.S., et al. Quality of life and the work capacity of professional nursing staff in the hospital environment. Bioscience Journal. 2021, 37, e37054. https://doi.org/10.14393/BJ-v37n0a2021-49982

\title{
Abstract
}

This study aimed to evaluate the association between life quality and the work capacity of nursing professionals in a public hospital of the public health system. A cross-sectional, quantitative study with the participation of 115 nursing professionals. The study method used the WHOQOL-brief questionnaire, the Work Capacity Index questionnaire, and a sociodemographic and occupational questionnaire. The data were analyzed through descriptive and inferential statistics, where values of $p \leq 0.05$ were considered significant. In terms of life quality, the domains that presented higher averages were for psychological $70.0 \pm 14.5$ and social relations $70.8 \pm 19.8$, with the physical domain reaching $64.4 \pm 11.9$ and the environment at $57.7 \pm 13.6$. The average score from the Work Capacity Index was 40.3 \pm 6.1 ; median: 42; IQR: 37.0-45.0), with a predominance of good and excellent for work capacity. Work capacity was increased for being male ( $\beta=3.99$; $p=0.016)$ and negatively associated to age $(\beta=-0.31 ; p<0.001)$. In conclusion, it is verified that there is a positive correlation between the capacity for work and the evaluation of the quality of life, but it is emphasized that the sociodemographic and occupational characteristics lead the nursing professional to present a work capacity reduction, which generates alterations in the perception of life quality.

Keywords: Life Quality. Nursing Profession. Nursing. Work Capacity Evaluation. Work. Workers Health.

\section{Introduction}

Work is considered as constituting the essence of the human being, it influences the daily routine, whether it be an element of growth and realization in the personal life of an individual or as an activity with little idealism, seen only to survive. Due to the macro history of work, it can be understood as an organizational factor for social life, and the relationship man has with the environment occurs through work, this is the concept one gains from logic according to capitalism. However, concerns linked to the health of the worker are only presented with greater emphasis with the advent of the industrial revolution (Borges and Bianchin 2015). 
In this context, one highlights that the health of the worker is complex, as it encompasses aspects such as Life Quality (LQ), conditions of the work environment, the occurrence of problems and accidents caused through risks related to the working environment, as well as the variety of aspects that involve the interaction between work and health. In such a scenario, the nursing professional plays an important role in recognizing these needs and puts forward propositions of intervention aimed at the adequacy of work to the worker (Marziale et al. 2010; Lino et al. 2012).

Nursing is composed of the highest number of professionals in the hospital and health institution establishments, with the commitment to aid and administration on a 24-hour basis; it possesses diverse organizational forms with methods and models that have contributed to the manifestation and precariousness of working conditions (Borges and Bianchin 2015).

The nursing professional constantly faces inappropriate working conditions, low pay, long working hours, and under-staffing that contribute to psychological and ergonomic implications on the health of the worker, thus generating alterations in $L Q$ and a reduction in work capacity (WC). It is pertinent to emphasize that in Brazil there exist few studies on the LQ, and WC directed toward the nursing professional (Queiroz and Souza 2012).

It is already known that there are several factors that reduce the LQ of workers, and these are largely linked to physical, psychological, technical, and social elements. Therefore, one can define LQ as the perception that the individual possesses in association with the position they hold in life, as with their objectives, expectations, standards, and concerns. Life Quality started to be evaluated in Brazil from the 1990's through the instrument elaborated by the life quality group from the World Health Organization, denominated as WHOQOL-100, which later was given greater suitability through its reduction to WHOQOLBref (Fleck 2000; Marques et al. 2015).

A good outlook on LQ provides the worker the means to look after their health and well-being during their professional lives, thus allowing for improvements to activities provided to the institution, which in turn, needs to stimulate the professional, in a manner that generates an improved WC and increases both productivity and satisfaction (Marques et al. 2015).

The evaluation of WC has been used in a number of Brazilian research studies, since the 1990's, using an instrument created by the Finnish Institute of Occupational Health -(FIOH). In terms of occupational health, WC can be conceptualized as how well the worker is presently doing and how well this is perceived to be for the immediate future, and how capable they will be for executing activities considering the demands made upon the job, the individual's health state along with their physical and mental capacities (Silva Júnior et al. 2011).

The Work Capacity Index (WCI) was translated to Portuguese by Fischer during the 1990's, and from that time until now, many studies involving workers in Brazil have employed the instrument in the evaluation of the capacity for executing work, as in the risk factors associated with performing the said capacity (Fischer et al. 2006; Renosto et al. 2009; Costa et al. 2012).

In the area of worker's health, emphasis is given to the importance and the need for more investigation concerning the relationship between $L Q$ and WC of nursing professionals, since workers with questionable quality of life indexes, often as a result of stressful and exhausting living conditions, often with double working hours, as well as inadequate and unhealthy work conditions to which they are subjected, as already investigated previously (Queiroz and Souza 2012; Paula et al. 2015), possibly present a reduced work capacity, reflected in a care and attention that is not adequate. In principle with the aim of understanding the work context and conditions, which can generate the possibility of improvement, progress and enhancement of health systems and the service provided through hospital institutions to the population in general. In fact, these are the professionals that are engaged in providing the attention and care given to patients, being a part of the pain, suffering, physical needs, and emotions of those attended to (Queiroz and Souza 2012).

Considering the above, the present study looks to understand if alterations of the perception in life quality interfere with the capacity to carry out the work functions demanded from nursing professionals in the hospital environment. Therefore, setting itself the objective of evaluating the association between life quality and the work capacity of nursing professionals in a public hospital in a municipal from the West Central of Brazil. 


\section{Material and Methods}

The cross-sectional quantitative study performed in a municipal hospital of the West Central of Brazil, in which the said municipal possesses a population of some 93,759 inhabitants, with five hospital care units. These are divided up in the following manner, one is private, one contracted to a company, two that are contracted out to private health insurance plans and the Health Unic System (HUS), and as such offer private health care assistance, providing general clinical assistance and psychiatry, and a unit of medium complexity with exclusive attendance to patients from HUS, with a 58-bed capacity, and a contingent of 145 nursing professionals (Jataí 2015). For the accomplishment of the present study, it was decided to research the hospital workers with exclusive care for the SUS in the city of Jataí, Goiás.

The nursing population in this study was constituted of 145 nursing professionals, from these staff with a minimum of six months of work and additionally had been carrying out their functions fully over this period were chosen. After submission to this selection process, there were 115 nursing professionals chosen to take part in the study from different shifts. This number was broken down as follows: 25 nurses, 84 technicians and 6 auxiliary nurses.

The collection of data was performed from May to June of 2016, at the participant's place of work, through the application of three instruments. The first, a sociodemographic questionnaire, elaborated by the very authors themselves and submitted for evaluation to five specialists in the area of worker's health. The second, the life quality questionnaire WHOQOL-Bref, (Fleck 2000) and finally the third, the questionnaire for the Work Capacity Index (WCI) (Renosto et al. 2009).

The WHOQOL-Bref questionnaire contains 26 questions (two general questions on Life Quality and 24 questions represent each of the 24 facets that constitute the original instrument the WHOQOL-100), in scale of the likert type, with scoring from 1 to 5 (Fleck 2000).

To calculate the domains, the WHOQOL - BREF, it is necessary that three questions have their scores inverted, and the final score result on a scale of 4 to 20, which can be transformed into a scale of 0 to 100 . The higher the score the better the quality-of-life perception (Fleck 2000).

The WCI was developed in Finland during the 1980's and is an instrument used to aid the professional to identify modifications in the function exercised at the workplace, thus preventing the risk of incapacity from the perception of the very professional themselves (Fischer et al. 2006).

The $\mathrm{WCl}$ questionnaire presents 7 items, with scores that vary from 7 to 49 points, and is calculated through the sum of each one of the seven items, where it is classified into four different categories of work capacity. Based on the final score, the results can reach scores of 7 to 49 points, with 7 to 27 being classified as a low work capacity, from 28 to 36 as moderate, from 37 to 43, as good, and 44 to 49 as excellent, according to Tuomi and IImarinen (1997) (Cerqueira and Freitas 2013).

The data were analyzed on the STATA software, version 12.0. To verify the normality of the quantitative variables, the Kolmogorov-Smirnov test was applied. Qualitative variables were presented as absolute and relative frequencies, and the quantitative variables as medians and standard deviation (SD), accompanied by their respective confidence intervals of $95 \%$ (CI 95\%) or in median and interquartile range (IQR), according to the data distribution.

Four outcome variables were considered for life quality related to domains: (i) physical; (ii) psychological; (iii) social relations and (iv) environment. Age (years), gender, income (Real Brazil), skin color, marital status, children, professional category, time in profession (months), weekly working hours, shift period, other current jobs and $\mathrm{WCl}$ were considered predictor variables.

To analyze work capacity, the outcome variable was considered as the scores on the WCI. Age (years), gender, income (Real Brazil), skin color, marital status, children, professional category, time in profession (months), weekly working hours, shift period, other current jobs and $\mathrm{WCl}$ were considered predictor variables.

Initially a bivariate analysis was performed conducted to verify the associations between the predictor variables with the life quality domains and with the $\mathrm{WCl}$. Due to the non-normality of the analyzed outcomes, the Mann-Whitney tests and Spearman correlation were used in this analysis. In the following, variables with values from $p<0.20$ and potential confounding variables (gender and age) were included in multiple linear regression models with robust variance. Values of $p \leq 0.05$ were considered statistically significant. 
The research study was approved by the Ethics Committee on Human Research at the Universidade Federal de Goiás, (Federal University of Goiás) under ruling 1.522.727, obeying the recommendations of Resolution No. 466, of 12 December 2012 of the National Health Council, maintaining the necessary procedures for assuring the reliability and the privacy of the participants.

\section{Results}

From the 145 nursing professionals, 115 (79.3\%) participated in the study. The 30 (20.7\%) nonparticipants resulted from refusal to participate in the study, vacations, leave of absence and a working period of less than six months. In terms of sociodemographic profile, there was a noted tendency in those participants to be of the female sex 101 (87.8\%), with an average age of $40.6( \pm 10.3)$ years, $37(22.2 \%)$ declared themselves white and in terms of marital status a majority live with a companion $60(52.2 \%)$ and 87 (75.7\%) had at least one child.

Regarding professional category, the majority were technicians or auxiliary nursing staff, totaling 90 (78.3\%) of professionals, followed by nurses, that sum up 25 (21.7\%) of professionals. They worked on average in the nursing area or were in the current function $140.9 \pm 118.4$ months (12.5 years), 69 (61.1\%) in the day shift and developed a workload with a mean of $44.1 \pm 14,8$ hours a week, with a monthly average income of $R \$ 3,440.00$ ( $\pm R \$ 2,338.4$ ), according to that presented on table 1 .

Table 1. Distribution of nursing professionals from the hospital environment, according to the sociodemographic and occupational data. Jataí, GO, Brazil, 2016. (n=115).

\begin{tabular}{lcc}
\hline \multicolumn{1}{c}{ Variables } & Sample & Percentage \\
\hline Gender & & \\
Female & 101 & 87.8 \\
Male & 14 & 12.2 \\
Marital status & 55 & 47.8 \\
Without companion & 60 & 52.2 \\
With companion & & \\
Skin color & 37 & 32.2 \\
White & 78 & 67.8 \\
Non white & & \\
Children & 87 & 75.7 \\
Yes & 28 & 24.3 \\
No & & \\
Shift & 69 & 61.1 \\
Day & 44 & 38.9 \\
Night & & \\
Professional category & 25 & 21.7 \\
Nurse & 90 & 78.3 \\
Technician/Auxiliary & Median & 10.3 \\
Age (years) & 40.6 & 2338.4 \\
Income (Brazilian Real) & 3440.0 & 118.4 \\
Working period (months) & 140.9 & 14.8 \\
Weekly working hours & 44.1 & \\
\hline
\end{tabular}

In terms of the analysis for the perception of general life quality, the scores found for the domains show lower averages for Physical 64.4 ( \pm 11.9 ) and Environment 57.7 ( \pm 13.6$)$. However, the domains that present higher averages were Psychology $70.0( \pm 14.5)$ and Social Relations $70.8( \pm 19.8)$. In the reliability analysis of the instrument, there was noted a good overall computing reliability, Cronbach alpha (0.680).

Regarding the results for the factors dealing with $L Q$, it was noted that the professionals that had companions presented better perception of LQ in the domains for Psychology $(p=0.07)$ and Social Relations $(p=0.020)$. For the domain of Environment, the best perceptions presented were for those professionals that did not have children $(p=0.024)$, are nurses $(p=0.038)$ and have companions $(p=0.013)$. For the qualitative 
variables, one noted a positive correlation for income, and negative for weekly hours worked with the environment domain. However, for the $\mathrm{WCl}$, all the domains present positive correlations, with a highly significant difference $(p<0.001)$, in accordance with table 2.

Table 2. Distribution of the sociodemographic variables and occupational aspects related to the quality of life in nursing professionals in the hospital environment. Jataí, GO, Brazil, 2016. ( $n=115)$.

\begin{tabular}{|c|c|c|c|c|c|c|c|c|}
\hline \multirow[b]{2}{*}{ Variables } & \multicolumn{2}{|c|}{ Physical } & \multicolumn{2}{|c|}{ Psychological } & \multicolumn{2}{|c|}{ Social Relations } & \multicolumn{2}{|c|}{ Environment } \\
\hline & $\begin{array}{c}\text { Average } \pm \\
\text { SD* }\end{array}$ & $\mathrm{p}^{+}$ & $\begin{array}{l}\text { Average } \pm \\
\text { SD* }\end{array}$ & $\mathrm{p}^{+}$ & $\begin{array}{l}\text { Average } \pm \\
\text { SD* }\end{array}$ & $\mathrm{p}^{+}$ & $\begin{array}{l}\text { Average } \pm \\
\text { SD }^{*}\end{array}$ & $\mathrm{p}^{\dagger}$ \\
\hline \multicolumn{9}{|l|}{ Gender } \\
\hline Female & $63,8 \pm 12,1$ & 0,125 & $69,2 \pm 14,4$ & 0,081 & $70,1 \pm 20,3$ & 0,203 & $57,1 \pm 13,9$ & 0.200 \\
\hline Male & $68,6 \pm 10,9$ & & $75,9 \pm 14,5$ & & $76,2 \pm 15,7$ & & $62,3 \pm 12,3$ & \\
\hline \multicolumn{9}{|l|}{ Children } \\
\hline Yes & $65,2 \pm 11,8$ & 0,459 & $69,2 \pm 14,4$ & 0,865 & $70,1 \pm 20,3$ & 0,934 & $57,1 \pm 13,9$ & 0.024 \\
\hline No & $68,6 \pm 10,9$ & & $75,9 \pm 14,5$ & & $76,2 \pm 15,7$ & & $62,3 \pm 12,3$ & \\
\hline \multicolumn{9}{|l|}{ Category } \\
\hline Nurse & $62,6 \pm 14,6$ & 0,731 & $70,0 \pm 14,9$ & 0,959 & $66,7 \pm 20,9$ & 0,161 & $63,5 \pm 13,1$ & 0.038 \\
\hline $\begin{array}{l}\text { Nursing } \\
\text { technician }\end{array}$ & $64,9 \pm 11,2$ & & $70,0 \pm 14,5$ & & $71,9 \pm 19,5$ & & $56,1 \pm 13,7$ & \\
\hline \multicolumn{9}{|l|}{ Skin color } \\
\hline White & $61,9 \pm 9,6$ & 0,147 & $69,2 \pm 15,1$ & 0,796 & $69,8 \pm 18,0$ & 0,527 & $57,2 \pm 11,1$ & 0.583 \\
\hline Non white & $65,6 \pm 12,8$ & & $70,4 \pm 14,3$ & & $71,3 \pm 20,7$ & & $57,9 \pm 15,0$ & \\
\hline \multicolumn{9}{|l|}{ Marital status } \\
\hline $\begin{array}{l}\text { Without } \\
\text { companion }\end{array}$ & $73,8 \pm 12,1$ & 0,122 & $65,9 \pm 15,1$ & 0,007 & $66,5 \pm 20,1$ & 0,020 & $54,5 \pm 13,3$ & 0.013 \\
\hline $\begin{array}{l}\text { With } \\
\text { companion }\end{array}$ & $66,4 \pm 11,6$ & & $73,7 \pm 12,9$ & & $74,7 \pm 18,7$ & & $60,6 \pm 13,8$ & \\
\hline \multicolumn{9}{|c|}{ Other occupation } \\
\hline Yes & $67,1 \pm 12,1$ & 0,110 & $72,8 \pm 13,3$ & 0,147 & $73,3 \pm 19,3$ & 0,337 & $60,1 \pm 13,5$ & 0.325 \\
\hline No & $62,8 \pm 11,8$ & & $68,4 \pm 14,6$ & & $68,9 \pm 20,2$ & & $56,3 \pm 13,6$ & \\
\hline \multicolumn{9}{|l|}{ Shift } \\
\hline Day & $61,1 \pm 11,7$ & 0,329 & $68,2 \pm 14,7$ & 0,224 & $69,2 \pm 21,0$ & 0,249 & $56,3 \pm 14,3$ & 0.256 \\
\hline Night & $66,5 \pm 12,6$ & & $72,3 \pm 13,9$ & & $74,2 \pm 16,7$ & & $60,0 \pm 13,1$ & \\
\hline Quantitative & Variation & $\mathrm{R} \ddagger$ & Variation & $\mathrm{R} \ddagger$ & Variation & $\mathrm{R} \ddagger$ & Variation & $\mathrm{R} \ddagger$ \\
\hline Age (years) & 0.048 & 0.610 & -0.079 & 0.400 & -0.056 & 0.549 & -0.186 & 0.046 \\
\hline $\begin{array}{l}\text { Income } \\
\text { (Brazilian Real) }\end{array}$ & 0.129 & 0.224 & 0.190 & 0,071 & 0.128 & 0.227 & 0.306 & 0.003 \\
\hline $\begin{array}{l}\text { Work period } \\
\text { (months) }\end{array}$ & -0.045 & 0.635 & -0.038 & 0.687 & -0.004 & 0.967 & -0.068 & 0.473 \\
\hline Weekly hours & -0.029 & 0.762 & 0.024 & 0.803 & -0.006 & 0.951 & -0.208 & 0.031 \\
\hline $\mathrm{WCl}^{\S}$ & 0.415 & $<0.001$ & 0.396 & $<0.001$ & 0.031 & $<0.001$ & 0.400 & $<0.001$ \\
\hline
\end{tabular}

*Standard deviation; †Mann-Whitney test; ¥Spearman correlation; ${ }^{\S}$ Work Capacity Index.

After the adjustment of the multivariable models, the $\mathrm{WCl}$ was checked for a positive association with life quality across all domains. In addition, professionals with a companion presented higher scores for life quality in the Psychology and Environment domain. The absence of other occupations was associated with the worst scores for life quality in the Physical domain, as shown on table 3. 
Table 3. Multivariable analysis associated to life quality in nursing professionals in the hospital environment. Jataí, GO, Brazil, 2016. ( $n=115)$.

\begin{tabular}{|c|c|c|}
\hline Variables & $\beta^{*}\left(\mathrm{RI}^{+} 95 \%\right)$ & $\mathrm{p}$ \\
\hline \multicolumn{3}{|l|}{ Physical Domain } \\
\hline $\mathrm{WCl}^{\ddagger}$ & $0.61(0.10 ; 1.11)$ & 0.018 \\
\hline \multicolumn{3}{|l|}{ Other occupation } \\
\hline Yes & Ref $^{\S}$. & \\
\hline $\mathrm{N}$ & $-6.76(-13.34 ;-0.17)$ & 0.044 \\
\hline \multicolumn{3}{|l|}{$R^{2}: 0.239$} \\
\hline \multicolumn{3}{|l|}{ Psychology Domain } \\
\hline \multicolumn{3}{|l|}{ Marital status } \\
\hline Without companion & $\operatorname{Ref}^{\S}$ & \\
\hline With companion & $8.70(2.88 ; 14.51)$ & 0.004 \\
\hline $\mathrm{WCl}^{\ddagger}$ & $0.67(0.16 ; 1.18)$ & 0.010 \\
\hline \multicolumn{3}{|l|}{$R^{2}: 0.245$} \\
\hline \multicolumn{3}{|l|}{ Social Relations Domain } \\
\hline $\mathrm{WCl}^{\ddagger}$ & $0.80(0.11 ; 1.49)$ & 0.023 \\
\hline \multicolumn{3}{|l|}{$R^{2}: 0.144$} \\
\hline \multicolumn{3}{|l|}{ Environment Domain } \\
\hline \multicolumn{3}{|l|}{ Marital status } \\
\hline Without companion & $\operatorname{Ref}^{\S}$ & \\
\hline With companion & $6.13(0.67 ; 11.59)$ & 0.028 \\
\hline $\mathrm{WCl}^{\ddagger}$ & $0.66(0.09 ; 1.22)$ & 0.022 \\
\hline$R^{2}: 0.144$ & & \\
\hline
\end{tabular}

*Regression coefficient; +Confidence interval; ${ }^{*}$ Work Capacity Index; Reference category ${ }^{\S}$.

The $\mathrm{WCl}$ instrument presented a Cronbach alpha of 0.719 , indicating a good internal reliability. The mean score for $\mathrm{WCI}$ was 40.3 ( \pm 6.1 ; mean: 42; IQR: 37.0-45.0). In terms of the WC classification for nursing professionals, it was noted that $6(5.2 \%$; $2.4-10.9)$ professionals presented low work capacity; 18 (15.7\%; 10.1-23.4), moderate capacity; 51 (44.3\%; 35.6-53.5), good capacity and 40 (34.8; 26.7-43.9), excellent capacity.

By dichotomising these categories, $20.9 \%(n=24)$ of the professionals possess low/moderate capacity (inadequate capacity for work), and $79.1 \%$ ( $n=91$ ) good/excellent capacity (adequate capacity for work).

When it comes to variable scores associated with WC, it was noted that for comparisons with the Physical domain, the professionals of male gender present higher WC ( $p=0.008)$. In terms of qualitative data, there was noted a negative correlation between age and work period $(<0.001$ and 0.015$)$ respectively, associated with WC in relation to the physical domain, as shown on table 4.

Table 4. Distribution of the correlation analysis between sociodemographic and occupational variables associated with work capacity in relation to the Physical domain concerning nursing professionals in the hospital environment. Jataí, GO, Brasil, 2016. ( $n=115)$.

\begin{tabular}{|c|c|c|}
\hline \multirow{2}{*}{ Variables } & \multicolumn{2}{|c|}{ Physical } \\
\hline & Mean $\pm S D^{*}$ & $\mathrm{p}^{+}$ \\
\hline \multicolumn{3}{|l|}{ Gender } \\
\hline Female & $39,7 \pm 6,2$ & 0.008 \\
\hline Male & $44,2 \pm 3,4$ & \\
\hline \multicolumn{3}{|l|}{ Children } \\
\hline Yes & $40,0 \pm 5,9$ & 0.272 \\
\hline No & $41,1 \pm 6,6$ & \\
\hline \multicolumn{3}{|l|}{ Category professional } \\
\hline Nurse & $41,7 \pm 4,9$ & 0.310 \\
\hline Nursing Technician & $39,9 \pm 6,4$ & \\
\hline \multicolumn{3}{|l|}{ Skin color } \\
\hline White & $39,3 \pm 6,3$ & 0.227 \\
\hline Black/brown & $40,7 \pm 6,0$ & \\
\hline
\end{tabular}




\begin{tabular}{lcc}
\hline Marital status & & \\
Without companion & $39,4 \pm 6,2$ & 0.076 \\
With companion & $41,1 \pm 5,9$ & 0.473 \\
Other occupation & & \\
Yes & $40,6 \pm 6,5$ & $39,9 \pm 5,9$ \\
No & & 0.869 \\
Shift & $40,0 \pm 6,7$ & $\mathrm{p}$ \\
Day & $40,9 \pm 5,3$ & $<0.001$ \\
Night & $\mathrm{R}^{\ddagger}$ & 0.128 \\
Age (years) & -0.331 & 0.015 \\
Income (Brazilian Real) & 0.161 & 0.233 \\
Work period (months) & -0.227 & -0.116 \\
Weekly hours & & \\
\hline
\end{tabular}

*Standard deviation; †Mann-Whitney test; ¥Spearman correlation.

In terms of factors associated with WC concerning nursing professionals, after adjustments to the linear regression model, verification was made as to whether the masculine gender had any increase to their score for WC $(\beta=3.99 ;(I C: 0.75 ; 7.24) ; p=0.016)$. It is also highlighted here that age was associated negatively to WC $(\beta=-0.31$; (IC: $-0.48 ;-0.14) ; p<0.001)$.

\section{Discussion}

The data observed in the present study confirms the results from other studies, in showing a predominance of the female gender in the nursing profession, which portrays historical and cultural aspects of the profession in that it has care as the main focus, which itself has always been associated with the female figure (Fernandes et al. 2012; Borges and Bianchin 2015).

Regarding gender and work hours, studies reveal that women have greater risk of presenting lower LQ and inadequate WC, mainly due to the lack of time available for leisure, a factor that was shown to contribute to promoting health and improving the perception of LQ (Maciel and Oliveira 2014). Most women assume a variety of roles and as such trigger the initiation of exhaustion into their daily lives, thus affecting LQ, through extensive workloads (double and triple loads), the housekeeping besides dedication with children and family, can also cause problems to physical as well as mental order (Vasconcelos et al. 2011; Maciel and Oliveira 2014).

In relation to the marital status found among nursing professionals, a study performed in a hospital in Midwest region, with 73 nursing technicians of both sexes, expressed that a majority $63.6 \%$ live with a companion and $69 \%$ had children, these data were close to those from the present study (Maciel and Oliveira 2014).

In terms of the age range, in the present study there was an observed average of 40.6 years of age, in the Literature there were findings of a similar nature in two studies conducted with nurses, both in a university hospital in the south of Brazil, where the respective averages were 41.7 and 42.6 years of age. This average indicates the need to implement strategies that aim at improving life quality, raise occupational health, thus benefitting the professionals of the institution, as it is recognized that the reduction in work capacity is associated with advanced age. (Hilleshein et al. 2011; Hilleshein and Lautert 2012).

The analysis of LQ can be influenced by multiple variables, and in the present study, perception was shown to have been impaired in the Physical and Environment domains and preserved in the Psychological and Social Relations domains.

When it comes to the Physical domain, a study performed with nursing professionals in a university hospital in southeastern Brazil also presented a low average (53.6) in respect to this domain. The professionals present discomfort in relation to conditions that involve their individual lives, expressed through physical pain, energy and tiredness, sleep, and rest among other aspects. Long working hours and conditions that are inadequate to the environment produce a situation where the professionals become physically more tired (Borges and Bianchin 2015). 
As much as the professionals from a hospital deal with the suffering of others, worry, sadness, which are factors that interfere in the psychological domain, scores with an average higher than (70.0) were attained in this domain, which is consistent with a study performed with nursing technicians from a hospital institution that found an average of 72.6 (Maciel and Oliveira 2014).

In the environment domain, recent studies with nurses and technicians/nursing auxiliaries from the hospital environment and family health strategy, conducted in the southeast and central west regions can explain the obtainment of a low score for this domain in the present study, which is related to security, healthy physical environment, financial resources, leisure, housing and transport, in that these professionals work in high risk occupational environments, without a qualified structure, night shifts in relation to the hospital environment, temporary work contracts, professional instability, among other factors that affect the score in this domain (Fernandes et al. 2012; Maciel and Oliveira 2014; Borges and Bianchin 2015; Marques et al. 2015).

In regards to factors associated with Life Quality within the studied population, a study conducted with nursing professionals at a large hospital of the central-western region of Brazil, showed that professionals who lived with a companion presented lower scores when compared to other domains, with an average of 55.4 in the Environment domain, when compared to those that live without a companion, and those that did not corroborate with this study, however, the professionals without a companion had a reduction in in their Life Quality score in the Environment, Social Relations, and Psychology domains (Queiroz and Souza 2012).

It is in all probability that this datum is associated to the fact that those who do not have a companion and have family responsibilities, domestic, financial, and social that are performed alone suffer greater strain and exhaustion, which can compromise their perception of life quality.

In this study there was an innovation encountered in relation to other occupational engagements, where it was observed that the absence of another occupation was associated with the worst scores for quality of life in the Physical domain. This can be explained in part through the idea that the professional that possesses more than one occupation can attain better financial conditions, and consequently participate in more activities associated with leisure, as well as possess more material wealth. This is contradictory to a study performed in Mexico that stated that professionals that possess another type of remunerated activity, show a decrease in life quality, in free time, and leads to physical and psychological problems in the work environment (Zavala et al. 2016).

In the $\mathrm{WCl}$ evaluation, there was a noted a higher proportion of good/excellent work capacity, with 79.1\% classifying themselves within the adequate for work capacity. In regard to the classification, another two studies with nursing professionals from the hospital environment performed in the south region corroborate with this study, with a predominance in the good/excellent capacity. However, the percentages were inferior to those found in the proposed study reaching a score of 56.7\% (Magnago et al. 2012; Magnago et al. 2015).

This demonstrates that although the nursing professionals from the hospital environment have an unfavorable environment, long working hours, high physical and mental demands, a majority point to an adequate working capacity, which does not eliminate the need to develop strategies that aim at reducing risk, promote health, maintenance, and improvements to work safety, with the objective of maintaining the professional healthy (Magnago et al. 2012; Magnago et al. 2015).

However, the findings from the present study concerning the $\mathrm{WCl}$ variables demonstrate a reduction in the work capacity in the female gender in relation to the male, which was the same as observed in the study performed with nursing professionals in an emergency and urgent care hospital a state in the northern region of the country, which obtained a score of $44.8 \%$ with an adjusted prevalence ratio of 1.8 and a confidence interval 1.1;3.2, thus the classification was of inadequate capacity for work (Vasconcelos et al. 2011).

Several factors can be considered when analyzing why women have a higher probability toward a reduction in WC, as they possess besides their professional activity with long working hours that are tiring, demands from extra family activities, as well as daily stress, which also go on to become factors that influence LQ (Vasconcelos et al. 2011). 
Regarding age and time of profession, these two factors come together to reduce the WC of the professional. The results from this study corroborate with various other studies developed until the present moment, where researchers observe that the higher the age group, lower will be the WC of the nursing professional, and the higher the time of profession, lower the WC (Hilleshein et al. 2011; Magnago et al. 2012; Prochnow et al. 2013; Magnago et al. 2015; Cossi et al. 2015).

Studies emphasize that age affects WC, as of 45 years of age, as it is from this age that morphologic and physiological alterations occur, such as body mass decrease, increase in adipose tissue, decrease in bone mass, among others. This goes on to cause a reduction in the function being performed, while generating stress and tiredness to the worker, due to those factors inherent to the work environment (Hilleshein et al. 2011; Magnago et al. 2012; Prochnow et al. 2013; Magnago et al. 2015; Cossi et al. 2015).

Through the study results, one infers that the population under study, in its majority, is satisfied with LQ and present satisfactory values for WC, even with the negative interference from the working environment, which corroborates with other studies related to nursing professionals. This reveals that perception of LQ of the professional is not only associated with work factors, but also with the perception of LQ from outside the working environment (Hilleshein et al. 2011; Queiroz et al. 2012; Costa et al. 2012; Maciel and Oliveira, 2014; Zavala et al. 2016).

Regarding $\mathrm{LQ}$, all the domains had an association with $\mathrm{WCl}$, thus showing a linear growth relationship, where the higher the score for LQ the higher also is the WC score of these professionals. In this sense, the relationship between LQ and WC is positive, showing that a satisfactory occupational capacity generates a profile for LQ that is also satisfactory for the professional, and vice versa. A study performed in the state one of the states of the Midwest, when studying nursing professionals in the hospital environment, proved that the more $\mathrm{WCl}$ decreased, also the LQ of professionals deteriorated, thus corroborating with the data of the present study (Queiroz et al. 2012).

However, for the population under study, the understanding of the importance of the research and to participate in it led to a certain level of limitation, due to the fatigue from nursing and a lack of information into its respect produces in such professionals a belief that it is not necessary to participate in research studies and do not understand the importance that the LQ and WC evaluation can provide them.

The main limitation of the study was the possibility of identifying cause and effect by a cross-sectional study, which could provide additional explanations about changes in QOL and consequently in the LQ. However, the study reveals the scenario in which nursing professionals are inserted, or what allows us to reflect on the need for joint actions to protect the health of this class of workers.

\section{Conclusions}

The findings from this study in relation to $L Q$ show a satisfactory $L Q$ among nursing professionals. Regarding WC, the data demonstrates the predominance of good/excellent, which proved that the professionals possess an adequate WC, and that management should support and maintain the WC of nursing professionals.

Noteworthy here is that the sociodemographic and occupational characteristics lead the nursing professional to present a reduction in work capacity, which generates alterations to their quality-of-life perception.

The evaluation of such becomes relevant considering that it provides support toward the understanding of the grievances generated by the work environment, which therefore offers managers the possibility to put into action improvements to working conditions, thus preventing impairment to health that may influence the loss of Work Capacity and a reduction in Life Quality.

Authors' Contributions: LIMA, C.S.: conception and design, acquisition of data, drafting the article; MAIA, L.G. and PELAZZA, B.B.: conception and design, analysis and interpretation of data, drafting the article; LEITE, S.T., BORGES, C.J. and MENDONÇA, G.S.: analysis and interpretation of data, drafting the article; SILVEIRA, S.E. and SANCHEZ, H.M.: conception and design, analysis and interpretation of data, drafting the article; SILVA, L.A.: conception and design, acquisition of data, analysis and interpretation of data, drafting the article. All authors have read and approved the final version of the manuscript.

Conflicts of Interest: The authors declare no conflicts of interest.

Ethics Approval: Approved by Ethics Committee on Human Research of Federal University of Goiás. Number: 2.434.059. 
Acknowledgments: The authors would like to thank all nursing workers participating in the study, who are daily sick as a result of their work.

\section{References}

BORGES, T. and BIANCHIN, M.A. Quality of life of nursing professionals at a university hospital in the inland of Sao Paulo. Arquivos de Ciências da Saúde. 2015, 22(1), 53-58. https://doi.org/10.17696/2318-3691.22.1.2015.29

CERQUEIRA, P.H.A. and FREITAS, L.C. Avaliação da Capacidade de Trabalho e do Perfil de Trabalhadores em Serrarias no Município de Eunápolis, BA. Revista Floresta. 2013, 43(1), 19-26. http://dx.doi.org/10.5380/rf.v43i1.26021

COSSI, M.S., et al. The ability to work of the nursing staff inserted in the hospital enviroment. Revista de Atenção à Saúde. 2015, 13(43), 5-9. https://doi.org/10.13037/rbcs.vol13n43.2374

COSTA, C.S.N., et al. Work ability and quality of life of Brazilian industrial workers. Ciência e saúde coletiva. 2012, 17(6), 1635-1642. http://dx.doi.org/10.1590/S1413-81232012000600026

FERNANDES, J.S., et al. The effects of professional factors on the quality of life of family health team nurses. Revista da Escola de Enfermagem da USP. 2012, 46(2), 404-412. http://dx.doi.org/10.1590/S0080-62342012000200019

FISCHER, F.M., et al. Workability of health care shift workers: what matters? Chronobiology International. 2006, 23(6), 1165-1679. https://doi.org/10.1080/07420520601065083

FLECK, M.P.A. The World Health Organization instrumentto evaluate quality of life (WHOQOL-100): characteristics and perspectives. Ciência e saúde coletiva. 2000, 5(1), 33-38. http://dx.doi.org/10.1590/S1413-81232000000100004

HILLESHEIN, E.F. and LAUTERT, L. Work capacity, sociodemographic and work characteristics of nurses at a university hospital. Revista. LatinoAmericana de Enfermagem. 2012, 20(3), 520-527. http://dx.doi.org/10.1590/S0104-11692012000300013

HILLESHEIN, E.F., et al. Work capacity of nurses in a university hospital. Revista Gaúcha de Enfermagem. 2011, 32(3), 509-515. http://dx.doi.org/10.1590/S1983-14472011000300011

JATAÍ (County). Profile of the city of Jataí. [internet] 2015 [cited Out 30, 2016]. Available from: http://www.jatai.go.gov.br/cidade-jatai/ LINO, M.M., et al. Occupational health nursing under the interdisciplinary view. Saúde \& Transformação Social. 2012, 3(1), 85-91.

MACIEL, M.E.D. and OLIVEIRA, F.N. Quality of life of professional technical of nursing: the reality of the philanthropic hospital in Dourados-MS. Revista Psicologia e Saúde. 2014, 6(1), 83-89.

MAGNAGO, T.S.B.S., et al. Intensity of musculoskeletal pain and (in) ability to work in nursing. Revista Latino-Americana de Enfermagem. 2012, 20(6), 1125-1133. http://dx.doi.org/10.1590/S0104-11692012000600015

MAGNAGO, T.S.B.S., et al. Relationship between work ability in nursing and minor psychological disorders. Texto \& Contexto-enfermagem. 2015, 24(2), 362-370. http://dx.doi.org/10.1590/0104-07072015002580013

MARQUES, A.L.N., et al. Quality of life and working context of nursing professionals of the Family Health Strategy. Rev Rene. 2015, 16(5), 672681. https://doi.org/10.15253/2175-6783.2015000500008

MARZIALE, M.H.P., et al. The roles and functions of occupational health nurses in Brazil and in the United States. Revista Latino-Americana de Enfermagem. 2010, 18(2), 182-188. http://dx.doi.org/10.1590/S0104-11692010000200007

PAULA, I.R., et al. Capacidade para o trabalho, sintomas osteomusculares e qualidade de vida entre agentes comunitários de saúde em Uberaba, Minas Gerais. Saúde e Sociedade. 2015, 24(1), 152-164. https://doi.org/10.1590/S0104-12902015000100012

PROCHNOW, A., et al. Work ability in nursing: relationship with psychological demands and control over the work. Reista. Latino-Americana de Enfermagem. 2013, 21(6), 1298-1305. http://dx.doi.org/10.1590/0104-1169.3072.2367

QUEIROZ, D.L. and SOUZA, J.C. Quality of life and capacity for work of nurses. Psicólogo InFormação. 2012, 16(16), 103-126.

http://dx.doi.org/10.15603/2176-0969/pi.v16n16p103-126

RENOSTO, A., et al. Test-retest reliability of the Work Ability Index (WAI) in metallurgy workers from Southern Brazil. Revista brasileira de epidemiologia. 2009, 12(2), 217-225. http://dx.doi.org/10.1590/S1415-790X2009000200011

SILVA JÚNIOR, S.H.A., et al. Validity and reliability of the work ability index (WAI) in nurses'work. Cadernos de Saúde Pública. 2011, 27(6), 10771087. http://dx.doi.org/10.1590/S0102-311X2011000600005

VASCONCELOS, S.P., et al. Factors associated with work ability and perception of fatigue among nursing personnel from Amazonia. Revista brasileira de epidemiologia. 2011, 14(4), 688-697. http://dx.doi.org/10.1590/S1415-790X2011000400015

ZAVALA, M.O.Q., KLINJ, T.P. and CARRILLO, K.L.S. Quality of life in the workplace for nursing staff at public healthcare institutions. Revista Latino-Americana de Enfermagem. 2016, 24(e2713), 1-8. http://dx.doi.org/10.1590/1518-8345.1149.2713

Received: 9 August 2019 | Accepted: 28 November 2019 | Published: 13 October 2021

This is an Open Access article distributed under the terms of the Creative Commons Attribution License, which permits unrestricted use, distribution, and reproduction in any medium, provided the original work is properly cited. 